\title{
A Case of Rectus Sheath Hematoma Due to Anticoagulants after Total Knee Arthroplasty
}

\author{
Wataru Shishikura, Hideyuki Aoki*, Takashi Nakamura, Yoshiyasu Miyazaki, \\ Takashi Saito, Ryo Takamatsu, Katsunori Fukutake, Kazuaki Tsuchiya \\ Department of Orthopedics, Toho University, Tokyo, Japan \\ Email: *wataru98050@yahoo.co.jp
}

Received 14 February 2016; accepted 31 May 2016; published 3 June 2016

Copyright (C) 2016 by authors and Scientific Research Publishing Inc.

This work is licensed under the Creative Commons Attribution International License (CC BY). http://creativecommons.org/licenses/by/4.0/

(c) (i) Open Access

\begin{abstract}
Background: Hematoma in the rectus sheath is not common but if happens it will become major bleeding. Sometimes anticoaglation of deep vein thrombosis (DVT) causes the hematoma in the rectus sheath. Case Report: A 74-year-old female patient after total knee arthroplasty (TKA) due to osteoarthritis. Postoperation, residual DVT was noted in the right soleus vein on ultrasonography of the veins of the lower limbs. Anticoaglation was started $7.5 \mathrm{mg} /$ day Arixtra for treatment of DVT. Anticoaglation was administered throughout rehabilitation, and abdominal pain developed on postoperative day 9 . Since respiratory distress developed on day 10 , then thoracoabdominal contrast CT was performed. Although no PE was observed, a hematoma was detected in the rectus sheath, and it perforated into the abdominal cavity. The hemoglobin level was reduced by about 4 $\mathrm{g} / \mathrm{dL}$, and the patient was admitted to the ICU. Surgical treatment was not performed, anticoagulant treatment was discontinued, and conservative treatment was administered. During management in the ICU, a total of 24 units of red blood cells were transfused. Conclusions: Rectus sheath hematoma should be in mind of surgeons during differential diagnosis of acute abdominal pain especially in patients receiving anticoagulants. Early recognition can be of great importance for patients' recovery, preventing from severe complications. Management is usually supportive although surgical intervention in some patients should be considered.
\end{abstract}

\section{Keywords}

Rectus Sheath Hematoma, TKA, Anticoagulation

\footnotetext{
${ }^{*}$ Corresponding author.
}

How to cite this paper: Shishikura, W., Aoki, H., Nakamura, T., Miyazaki, Y., Saito, T., Takamatsu, R., Fukutake, K. and Tsuchiya, K. (2016) A Case of Rectus Sheath Hematoma Due to Anticoagulants after Total Knee Arthroplasty. Open Journal of Orthopedics, 6, 135-138. http://dx.doi.org/10.4236/ojo.2016.66020 


\section{Introduction}

Deep vein thrombosis (DVT) after total knee arthroplasty (TKA) is a serious complication that may cause pulmonary thromboembolism. However, hemorrhagic adverse reactions to anticoagulants have been occasionally reported. We encountered a patient in whom thrombolytic therapy was administered to prevent DVT after TKA and induced hematoma in the rectus sheath. We report this case with a review of the literature.

\section{Case Report}

A 74-year-old female patient was admitted to the orthopaedics of our hospital due to the severe right knee joint pain. Her right knee joint showed varus deformity, and the range of motion was limited, extension was $-5^{\circ}$ and flexion was about $90^{\circ}$. She could only walk $300 \mathrm{~m}$ because of the right knee joint pain. Plain radiography shows narrowing of the medial joint space and loose body in the joint were noted in the frontal view while standing, and narrowing of the femoropatellar joint was noted in the axial view. The femorotibial angle was $184^{\circ}$. TKA was performed using FINE® Total Knee System (Nakashima Medical Co., Ltd.).

Operative time was 95 minutes, the postoperative blood loss was about $400 \mathrm{ml}$. The patient became ambulatory and started rehabilitation on postoperative day 1 . From postoperative day 2, preventive anticoagulant administration of fondaparinux sodium (Arixtra; $2.5 \mathrm{mg} /$ day) was initiated after removal of the drain placed in the joint and epidural anesthesia. Postoperative day 4, residual DVT was noted in the right soleus vein on ultrasonography of the veins of the lower limbs (Figure 1). Chest contrast CT was performed on day 5, and no pulmonary thromboembolism (PE) was evident. However, thrombolytic therapy with $7.5 \mathrm{mg} /$ day Arixtra was requested and initiated by the Department of Cardiology. Thrombolytic therapy was administered throughout rehabilitation, and abdominal pain developed on postoperative day 9. Since respiratory distress developed on day 10, then thoracoabdominal contrast CT was performed. Although no PE was observed, a hematoma was detected in the rectus sheath, and it perforated into the abdominal cavity (Figure 2). The hemoglobin level was reduced by about $4 \mathrm{~g} / \mathrm{dL}$, and the patient was admitted to the ICU. Surgical treatment was not performed, anticoagulant treatment was discontinued, and conservative treatment was administered. During management in the ICU, a total of 24 units of red blood cells were transfused. The disease condition stabilized on postoperative day 21 , and the patient became able to reinitiate rehabilitation.

\section{Discussion}

It is common to use anticoagulant in DVT prophylaxis of after arthroplasty. But the anticoagulation therapy is feared an increase in bleeding events, useless it is better not to perform. Recently, anticoagulation therapy has been started in the NOAC, bleeding events than VKA is small but it is necessary to pay attention [1]-[3].
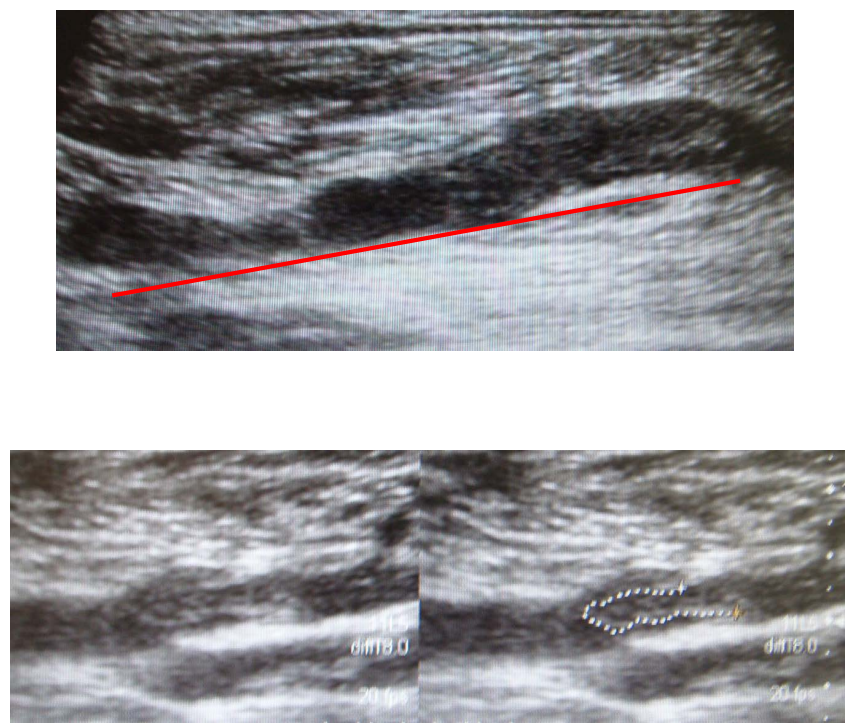

Figure 1. DVT of length $6 \mathrm{~cm}$ occurred to right soleus vein (line). 


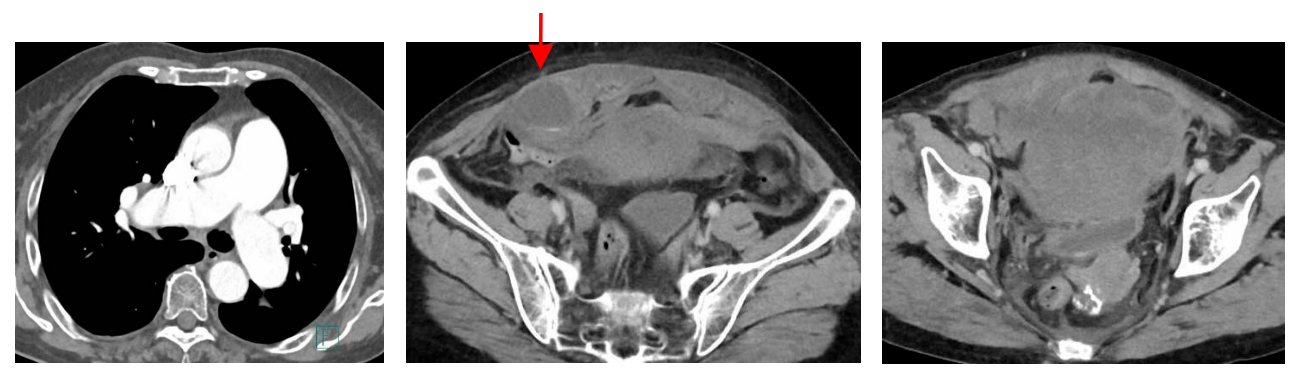

Figure 2. Axial view computed tomographic scan revealing hematoma within the rectus sheath (arrow).

In rectus sheath hematoma, hemorrhage caused by breakage of the superior and inferior epigastric arteries and veins and muscle fibers leads to the formation of a hematoma in the abdominal wall. The main risk factors for rectus sheath hematoma are anticoagulant therapies [4] [5], coagulation disorders, previous surgical operations [6], abdominal trauma, increased intra-abdominal pressure [7]-[9]. Other causes have been also described in case reports, such as acupuncture [10], subcutaneous injection, foley catheterization [11], HCV-related mixed cryoglobulinemia [12], lymphoproliferative disease after renal transplantation [13], and tetanus [14].

The symptoms are the sudden development of abdominal pain and an abdominal mass.

The role of ultrasonography and computed tomography is crucial, although computed tomography appears to be the most accurate way of confirming the diagnosis [15].

Rectus sheath hematoma management is mainly supportive, including immobilization, Cessation of anticoagulation therapy, and surgery is considered when hemorrhage persists. To our knowledge, there have been no reports of rectus sheath hematoma due to anticoagulant therapy following TKA, but rehabilitation and the use of anticoagulants following TKA may be additional risk factors for rectus sheath hematoma.

TKA is a high-risk of DVT, the cause is deep flexion and tourniquet during surgery, and include muscle relaxation due to spinal anesthesia. After surgery of TKA is the use of preventive anticoagulation is a basic, but Asymptomatic or symptomatic DVT will develop still in about 30\% of patients. The potential measures against thromboembolism (VTE) after TKA were changed in the Antithrombotic Therapy and Prevention of Thrombosis, $9^{\text {th }}$ ed.: American College of Chest Physicians Evidence-Based Clinical Practice Guidelines (ACCP guidelines) revised in 2012. When the $8^{\text {th }}$ and $9^{\text {th }}$ editions were compared, measures against asymptomatic VTE were described in the $8^{\text {th }}$ edition, but symptomatic VTE was targeted in the $9^{\text {th }}$ edition, and the grade for postoperative use of anticoagulants was reduced from 1 to 2 . These may have been due to an increase in the incidence of hemorrhagic events due to excessive use of anticoagulants. In the $9^{\text {th }}$ edition of the ACCP guidelines, imaging observation at 2 weeks is recommended, as Grade 2B when distal DVT has no risk of progressing toward the proximal side. Our case was distal DVT that was a solitary residual thrombus in the soleus vein and the length was about $5 \mathrm{~cm}$. No PE was observed. Considering these findings, it was very likely that oral anticoagulant treatment at a preventive dose and course observation with physical therapy, such as rehabilitation, were appropriate. However, no treatment has been clearly established for such cases in the current guidelines.

\section{Conclusion}

Rectus sheath hematoma should be in mind of surgeons during differential diagnosis of acute abdominal pain especially in patients receiving anticoagulants. Early recognition can be of great importance for patients' recovery, preventing from severe complications. Management is usually supportive although surgical intervention in some patients should be considered.

\section{Consent}

Written informed consent was obtained from the patient for publication of this case report and any accompanying images.

\section{References}

[1] Hokusai-VTE Investigators (2013) Edoxaban versus Warfarin for the Treatment of Symptomatic Venous Throm- 
boembolism. The New England Journal of Medicine, 369, 1406-1415. http://dx.doi.org/10.1056/NEJMoa1306638

[2] ARISTOTLE Committees and Investigators (2011) Apixaban versus Warfarin in Patients with Atrial Fibrillation. The New England Journal of Medicine, 365, 981-992.

[3] The ROCKET AF Investigators (2011) Rivaroxaban versus Warfarin in Nonvalvular Atrial Fibrillation. The New England Journal of Medicine, 365, 883-891. http://dx.doi.org/10.1056/NEJMoa1009638

[4] Sullivan, L.E.J., Wortham, D.C. and Litton, K.M. (2014) Rectus Sheath Hematoma with Low Molecular Weight Heparin Administration: A Case Series. BMC Research Notes, 7, 586. http://dx.doi.org/10.1186/1756-0500-7-586

[5] Elikowski, W., Małek, M., Klich, A., Wróblewski, D. and Gizło, J. (2012) Rectus Sheath Hematoma: A Rarely Diagnosed Complication of Anticoagulation Therapy. Polski Merkuriusz Lekarski, 32, 309-312.

[6] Procacciante, F., Diamantini, G., Paolelli, D. and Picozzi, P. (2009) Rectus Sheath Hematoma as an Early Complication of Laparoscopic Hemicolectomy: A Case Report and Review of the Literature. Chirurgia Italiana, 61, 481-483.

[7] Choi, Y. and Lee, D. (2009) A Case of Rectus Sheath Hematoma Caused by Yoga Exercise. The American Journal of Emergency Medicine, 27, 899.el-899.e2.

[8] Barna, L., Toth, I., Kovacs, E. and Krizso, E. (2009) Rectus Sheath Hematoma Following Exercise Testing: A Case Report. Journal of Medicine Case Reports, 3, Article 9000.

[9] Tolcher, M.C., Nitsche, J.F., Arendt, K.W. and Rose, C.H. (2010) Spontaneous Rectus Sheath Hematoma Pregnancy: Case Report and Review of the Literature. Obstetrical and Gynecological Survey, 65, 517-522. http://dx.doi.org/10.1097/OGX.0b013e3181f87eaf

[10] Cheng, S.P. and Liu, C.L. (2005) Rectus Sheath Hematoma after Acupuncture. Journal of Emergency Medicine, 29, 101-102. http://dx.doi.org/10.1016/j.jemermed.2005.01.010

[11] Choi, Y.H., Lee, D.H., Yun, S.Y. and Lee, J.H. (2012) A Case of Rectus Sheath Hematoma Due to Foley Catheterization after Acute Urinary Retention. The American Journal of Emergency Medicine, 30, 837.e3-837.e4.

[12] Moschella, C.M., Palmieri, I., Bartolucci, P., Assenza, M., Maiuolo, A. and Modini, C. (2002) Spontaneous Rectus Sheath Hematoma in HCV Mixed Cryoglobulinemia Requiring Emergency Treatment (Case Report). Il Giornale di Chirugia, 23, 331-333.

[13] Franco, A., Jimenez, L., Munoz, C., Chulia, M., Marco, P. and Munoz, E. (2000) Hematoma of the Anterior Rectus Abdominis Muscle as the First Manifestation of Lymphoproliferative Disease after Renal Transplantation. Nefrologia, 20, 559-562.

[14] Suhr, G.M. and Green Jr., A.E. (1989) Rectus Abdominis Sheath Hematoma as a Complication of Tetanus. Diagnosis by Computed Tomography Scanning. Clinical Imaging, 13, 82-86. http://dx.doi.org/10.1016/0899-7071(89)90132-0

[15] Moreno Gallego, A., Aguayo, J.L., Flores, B., et al. (1997) Ultrasonography and Computed Tomography Reduce Unnecessary Surgery in Abdominal Rectus Sheath Hematoma. British Journal of Surgery, 84, 1295-1297. http://dx.doi.org/10.1046/j.1365-2168.1997.02803.x 